\title{
Editorial: AJUR and the Flat World
}

\author{
C. C. Chancey, Editor \\ American Journal of Undergraduate Research \\ University of Northern lowa \\ Cedar Falls, lowa 50614-0150 USA
}

\begin{abstract}
A recent bestseller in the United States has reminded people here of something that science and technical professionals around the world have known for some time: technical prowess is no longer a limited or geographically-isolated commodity. The book, The World Is Flat: $A$ Brief History of the Twenty-first Century by Thomas L. Friedman, argues that increased global wealth and the rise of technically trained middle classes in countries like India and China have shortened the supply chain for manufacturing and services between countries. Services and manufacturing, even in high-technology areas, now likely as not involve cooperative ventures on a global scale. Competition for markets is played out on a much more level field (or "flat world") than was the case a generation ago.

Science has always had widerranging connections than other areas of human endeavor. Of course, resources for science have often been unequally spread across the globe-a scientifically-employed
\end{abstract}

middle class almost always requires a much larger mercantile middle class. Even so, high-quality research has had an international flavor, with collaboration large and small the norm.

What is new is the "flatness" of the undergraduate research world. Research papers in this journal have come increasingly from undergraduate researchers who are outside the US. AJUR papers illustrate this trend. The graphic below shows the research location of papers published in AJUR since vol. 1, no. 1, in June 2002. Locations before December 2004 are marked with a dot (•); those in the last year from December 2004 are marked with a diamond $(\bullet) .60 \%$ of all non-US papers published have appeared in the last year (6 of 10). Current submissions indicate that this shift will likely continue and grow. Science has always been fortunate to have broad representation, and AJUR is fortunate to be maturing into an international forum in this new flatter world.

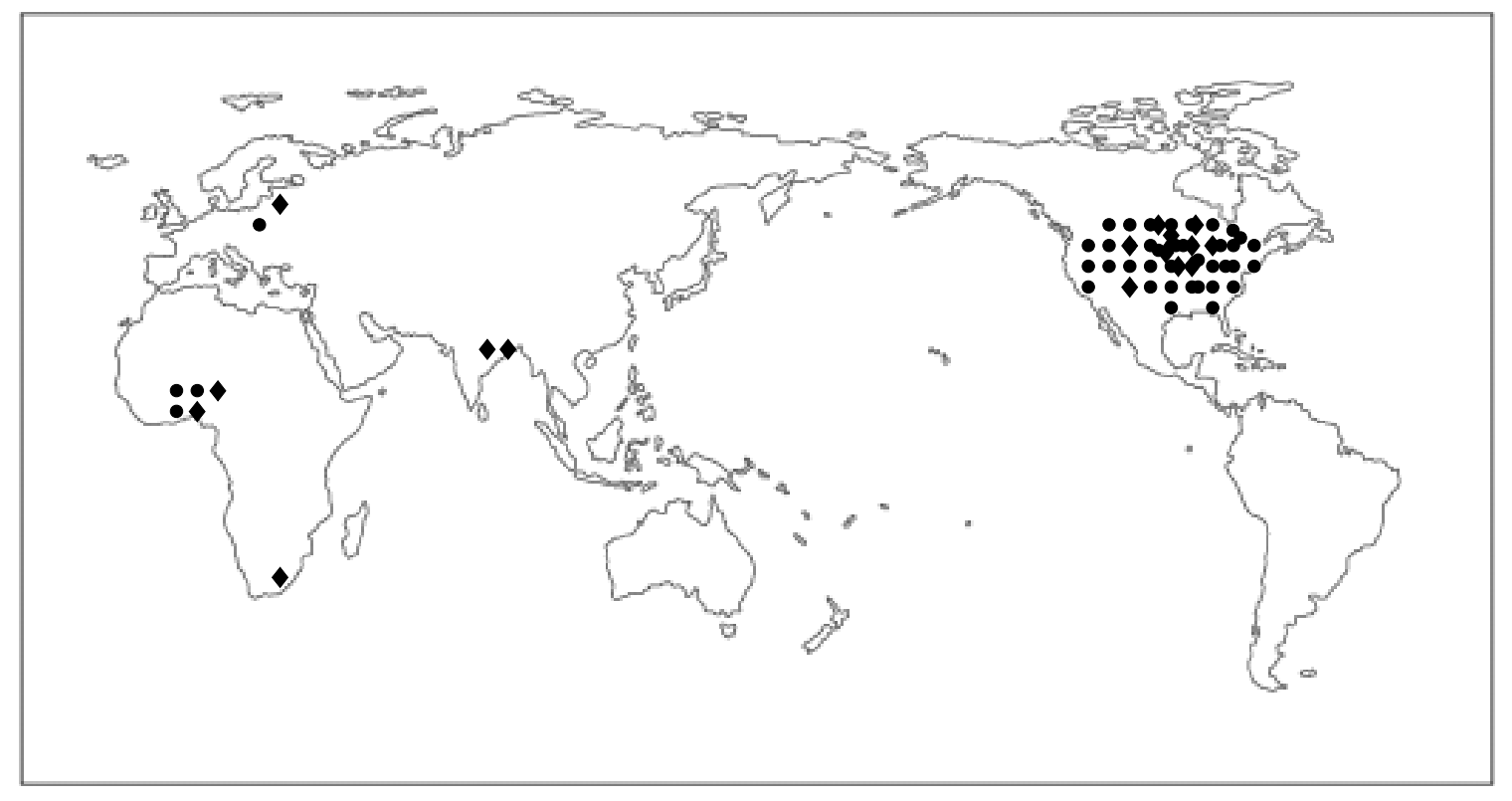

